\title{
Technical note: Stage and water width measurement of a mountain stream using a simple time-lapse camera
}

\author{
Pauline Leduc $^{1}$, Peter Ashmore ${ }^{1}$, and Darren Sjogren ${ }^{2}$ \\ ${ }^{1}$ University of Western Ontario, Department of Geography, London, Ontario, Canada \\ ${ }^{2}$ University of Calgary, Department of Geography, Calgary, Alberta, Canada \\ Correspondence: Pauline Leduc (pleduc3@uwo.ca) \\ Received: 15 May 2017 - Discussion started: 18 July 2017 \\ Revised: 30 October 2017 - Accepted: 2 November 2017 - Published: 3 January 2018
}

\begin{abstract}
Remote sensing applied to river monitoring adds complementary information useful for understanding the system behaviour. In this paper, we present a method for visual stage gauging and water surface width measurement using a ground-based time-lapse camera and a fully automatic image analysis algorithm for flow monitoring at a river cross section of a steep, bouldery channel. The remote stage measurement was coupled with a water level logger (pressure transducer) on site and shows that the image-based method gives a reliable estimate of the water height variation and daily flow record when validated against the pressure transducer $(R=0.91)$. From the remotely sensed pictures, we also extracted the water width and show that it is possible to correlate water surface width and stage. The images also provide valuable ancillary information for interpreting and understanding flow hydraulics and site weather conditions. This image-based gauging method is a reliable, informative and inexpensive alternative or adjunct to conventional stage measurement especially for remote sites.
\end{abstract}

\section{Introduction}

Conventionally, river discharge is gauged using continuous measurement of stage (typically, at temporary sites, using a pressure transducer and data logger) that is converted to continuous discharge data using a stage-discharge curve established for the site. In some cases, installation of a stage recorder is problematic and in complex flows interpretation of stage fluctuations may be uncertain. These conditions may arise, for example, in steep, bouldery or rock bed channels. Image-based measurements may provide equivalent data to the pressure transducer record while giving additional information such as water width, state of flow, water surface configuration and indications of flow hydraulics. For larger rivers, satellite or aerial images may provide useful streamgauging data (e.g. Smith et al., 1996; Gleason and Smith, 2014), but for small streams and very high frequency (minutes) over extended periods, satellite and airborne platforms do not provide sufficient resolution or temporal frequency (Gleason et al., 2015). Ground-based remote sensing provides a wide range of data for many applications for monitoring river flow and morphology especially in smaller channels or where high-frequency data are needed for extended time periods (Bertoldi et al., 2012; Williams et al., 2011; Javernick et al., 2014; Gleason et al., 2015).

Remote sensing based on photogrammetry technology provides an efficient topographic tool and access to topography and hydraulic characteristics (Javernick et al., 2014). However, the large amount of data needed to generate topography makes it difficult to apply on small streams with a high sampling frequency (Gleason et al., 2015).

In relation to flow characteristics, water surface width can be measured from ground-based cameras (Ashmore and Sauks, 2006; Gleason et al., 2015) and correlated with discharge to establish a width-discharge curve in some types of rivers, and local flow velocity has been measured using particle image velocimetry (Creutin et al., 2003; Hauet et al., 2008; Tsubaki et al., 2011; MacVicar et al., 2012; Ran et al., 2016; Stumpf et al., 2016). Direct measurement of stage is less well developed, although Young et al. (2015) obtained a water level and discharge record using manual image processing on a small, steep channel using inexpensive groundbased cameras combined with channel geometry and rough- 
ness assumptions. A more automated method that does not require manual image classification and channel geometry and hydraulic assumptions would be useful.

Methods for automated image selection and measurement are also needed in order to process $10^{3}$ or $10^{4}$ images that may come from high-frequency time-lapse red-green-blue (RGB) imagery (Gleason et al., 2015). Here, we test a simple time-lapse camera system for directly measuring stage and water surface width using image classification, and develop automated image selection and classification processes that retain a much larger proportion of the images than the process described by Gleason et al. (2015). We apply the method to monitor flow in a steep, bouldery, glacier-fed mountain stream which presents challenges for any form of flow gauging.

\section{Measurement method}

\subsection{Site}

The study site is located on a small, steep, bouldery reach of a stream, approximately $100 \mathrm{~m}$ downstream of the outlet from the small pro-glacial lake of the Dome Glacier, in Jasper National Park, Alberta, Canada (Fig. 1).

The site elevation is about $1800 \mathrm{~m}$ above sea level and the upstream drainage area is primarily the subglacial drainage of the Dome Glacier which is about $3 \mathrm{~km}$ in area. The stream is a left bank tributary of the Sunwapta River, and the primary purpose of the study is to better estimate the total discharge of a braided section of the river downstream of the SunwaptaDome Glacier tributary confluence by directly monitoring the Dome Glacier streamflow during the summer meltwater flow season. The Water Survey of Canada gauging station on the Sunwapta River, at the outlet of the pro-glacial Sunwapta Lake, a few hundred metres upstream of the confluence with the Dome Glacier stream (Fig. 1), provides detailed discharge records for the braided reach but does not account for the tributary contribution. Ashmore and Sauks (2006) measured water surface width from oblique timelapse images on the braided reach of Sunwapta River downstream of this tributary and established a relationship with discharge at the Water Survey of Canada gauging station using a small number of gauging measurements in the braided reach. However, continuous measurement of the discharge of the Dome Glacier stream has not previously been used for monitoring this narrow, steep tributary to directly measure its contribution, daily flow variation and timing of daily peak flow relative to the Sunwapta River discharge. The stream flow is mainly controlled by snow and glacier melt in summer producing a regular diurnal hydrograph with long-period changes due to average air temperature and synoptic weather conditions in the summer. A straight, single thread reach of the channel was chosen for the gauging location.

\subsection{Field setting}

The main objective of the study was to use ground-based remote sensing to measure the flow characteristics (flow stage and water surface width) and peak flow periods in the daily flow cycle in this pro-glacial stream and assess the flow and timing of peaks relative to the flow of Sunwapta River. Standard pressure transducer measurement of stage is possible at this site (and is used here for comparison with imagebased measurements) but we are interested in testing whether reliable image-based measurements are possible to complement or replace stage-only data with water level, water surface width and state of flow information from remote camera monitoring. A Reconyx HyperFire camera was set on the right side of the reach (Fig. 2), clamped to a pole hammered into the rocky ground, facing an almost vertical face of a large boulder on the opposite bank of the river. The entire stream width is visible in the pictures (Fig. 3).

Pictures were taken every $15 \mathrm{~min}$ during daylight (typically 06:00-22:00 MST (UTC - 6) at this location in the summer, and the daily peak was usually 16:00-19:00 MST) which corresponds to the sampling interval and timing of the gauging station on the Sunwapta River. During the study period, from 13 June to 22 September 2015, 7284 pictures were taken, saved on an SD card and downloaded at the end of the study period. Two stage boards were installed - one on each side of the stream (Fig. 3). On the left bank, a water level logger was installed in a vertical pipe in the stream bed next to the stage board with stage recorded at $15 \mathrm{~min}$ intervals throughout the study period for comparison with the image-based stage data. Level data were compensated for atmospheric pressure. The boulder has an almost vertical surface facing the camera, and it was calibrated for stage measurement in addition to the stage boards.

In the rest of the paper, the phrase "transducer data set" and the notation $H_{\text {transducer }}$ correspond to the stage coming from the pressure transducer, and the phrase "camera data set" and notation $H_{\text {camera }}$ correspond to the stage coming from the image analysis.

\section{Stage and water width measurement}

\subsection{Picture quality}

A goal of this method is to minimize any manual treatment of the images to select an analysis set of images and to estimate water stage and water width from those images. Consequently, a screening treatment was applied to remove unusable pictures prior to analysis. The initial RGB picture size is $2048 \times 1536$ pixels, which was saved in .jpg format and converted into grey scale. Dark pictures corresponding to twilight and night were identified using a very low standard deviation of the grey intensity of the picture and automatically deleted from the data set. Over the summer, weather condi- 

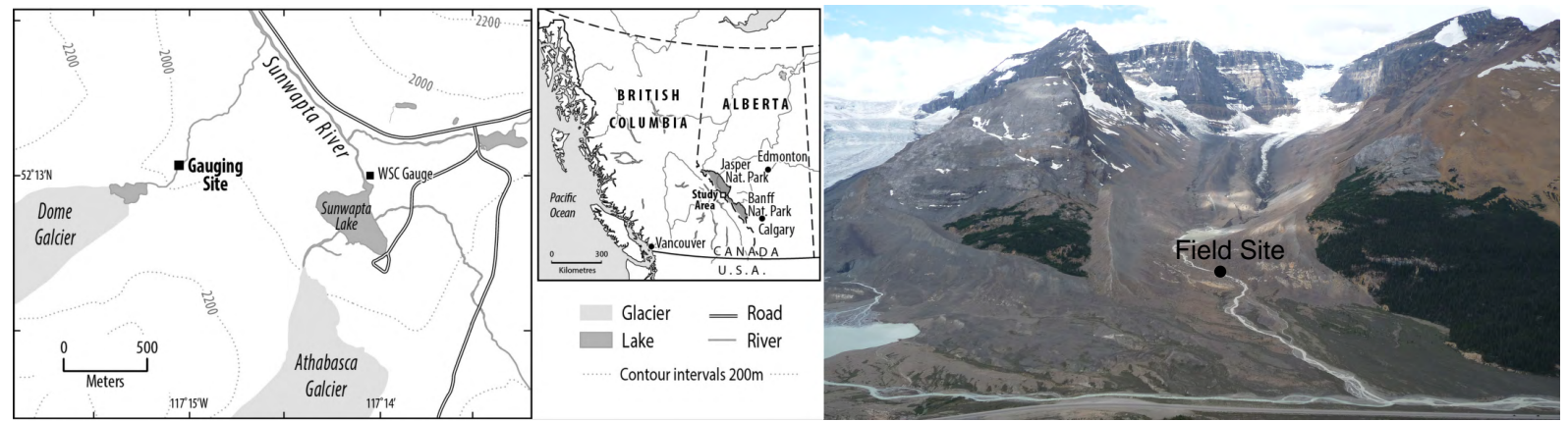

Figure 1. Map of the site location (left) and view of the Dome stream (right); image attribution - J. T. Gardner.

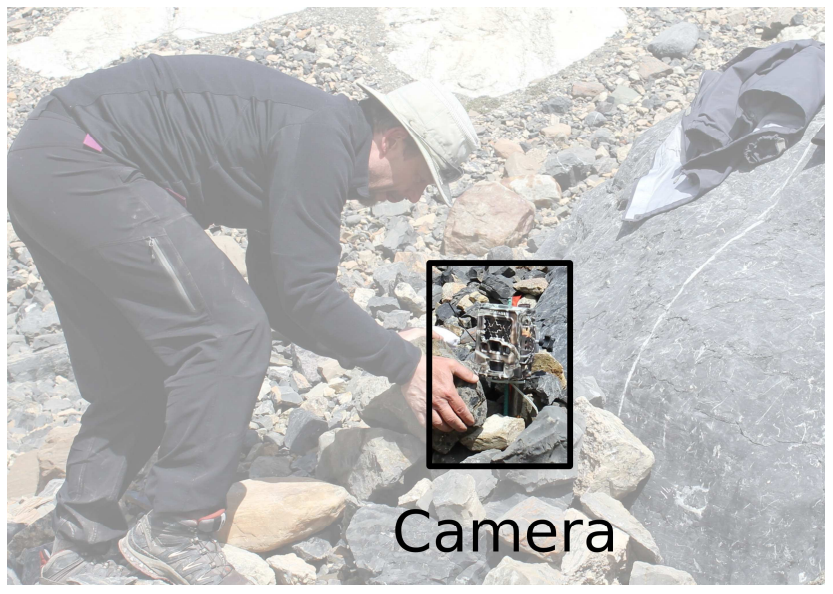

Figure 2. Camera setup. The camera is set on the right bank of the stream, a few metres above the water level. The camera is clamped to a pole hammered into the ground.

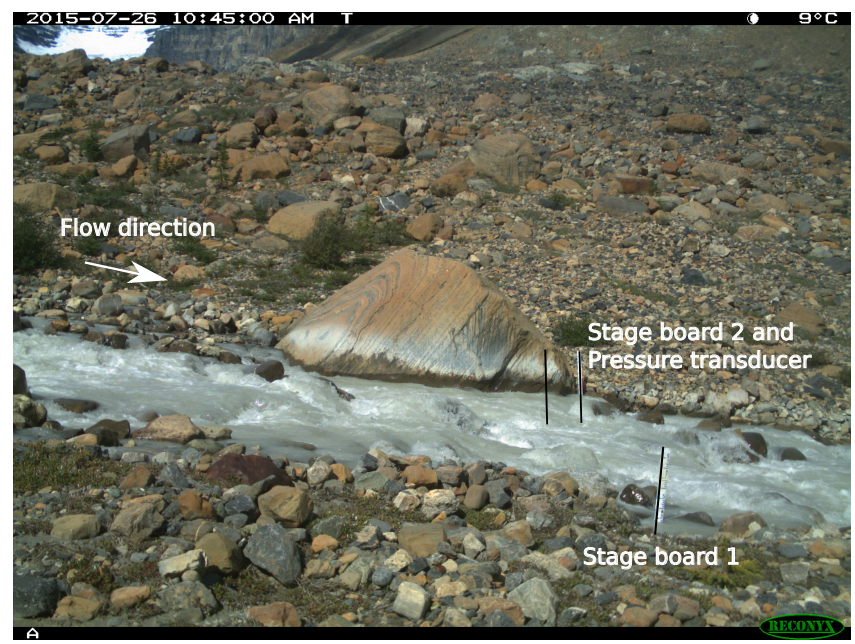

Figure 3. Reconyx raw picture showing the installation of stage boards, pressure transducer and boulder used for gauging (centre of picture). Black lines represent the three different tested profiles. tions also negatively impacted image quality. During rain or snow episodes, the images are blurrier and water drops on the camera block the view. Snow cover on the ground is a lighter shade than the water, the opposite of the normal weather conditions. In the late afternoon and evening, the Sun shines into the camera and induces two kinds of issues. First, sunlight directly hits the camera and the picture is almost entirely saturated. Second, the water surface is saturated by reflections and the boulder facing the camera creates a large dark shadow on the water surface. Each of these issues interferes with the image processing and had to be compensated for.

For all the previous reasons (rain, drops on the lens, snow, Sun effects), and as mentioned in Gleason et al. (2015) and Young et al. (2015), pictures have to be classified. We developed automatic classification processes and set two different output options: (1) the image is removed from the data set or (2) the image is retained but different processes of classification and water surface detection are used for particular conditions (see Sect. 3.2).

\subsection{Picture classification}

Image quality issues arise throughout the process of water detection and width estimation: poor weather conditions (Fig. 4a), shadows (Fig. 4b), emerged rocks in the stream (Fig. 4c) and light snow cover on the edge on the stream (Fig. 4d).

To deal with those four issues, four different selection tests based on different target zones in the images were applied before or during the stage and water width measurements. All four tests were applied to the grey-scale pictures and in the following descriptions of standard deviations or averages refer to calculations on pixel intensity.

The first test was made to remove pictures taken under bad weather conditions (heavy snow or rain episodes, and sunlight directly into the camera) and it is based on the rocky zone target on the left of the picture (Test 1, area 1 in Fig. 5).

The standard deviation of this surface is high due to the apparent roughness coming from the rocky surface. Under adverse weather conditions, that area is smoother and the standard deviation drops (snow cover with normal weather con- 


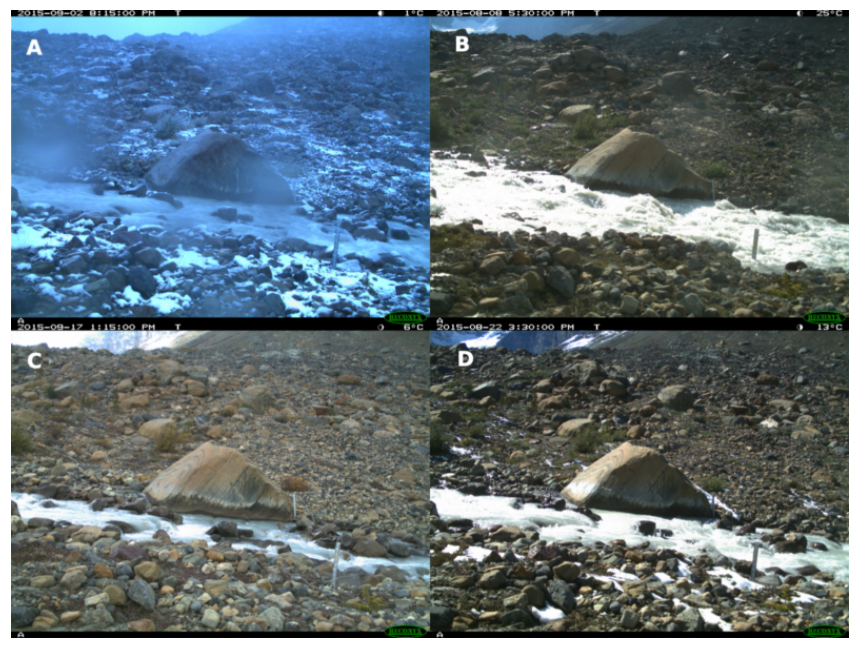

Figure 4. Images illustrating the main issues affecting image quality and measurements during the stage and width calculation: (a) heavy weather conditions, (b) boulder shadow and intense water reflection, (c) emerged rocks on the main channel at low flows and (d) light snow cover on the edge of the stream.

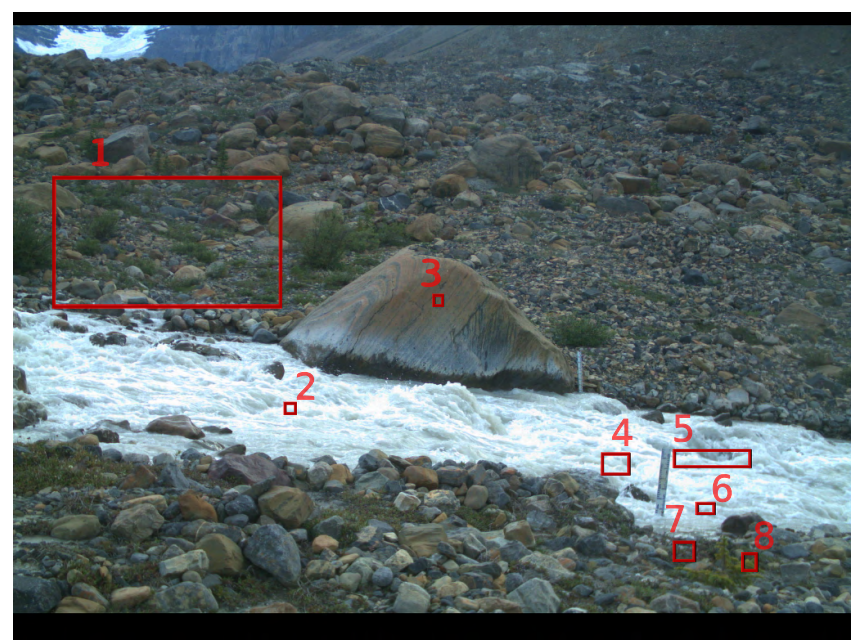

Figure 5. The eight different targets zones used in the picture classification process.

dition is not included in that test because, even with snow, the roughness from the block elevation makes the standard deviation high enough) and the picture was removed from the data sets. Of the 6717 pictures, $12 \%$ were removed after this test (Fig. 6).

During the water surface detection, a significant boulder shadow sometimes interfered with the detection. Figure 5 shows target zones 2 and 3 that were used to detect the boulder shadow (Test 2), combining a height reflectance of the water (on zone 2) and a dark zone on the boulder face (on zone 3). A different water detection threshold was applied for those pictures (see Sect. 3.3).

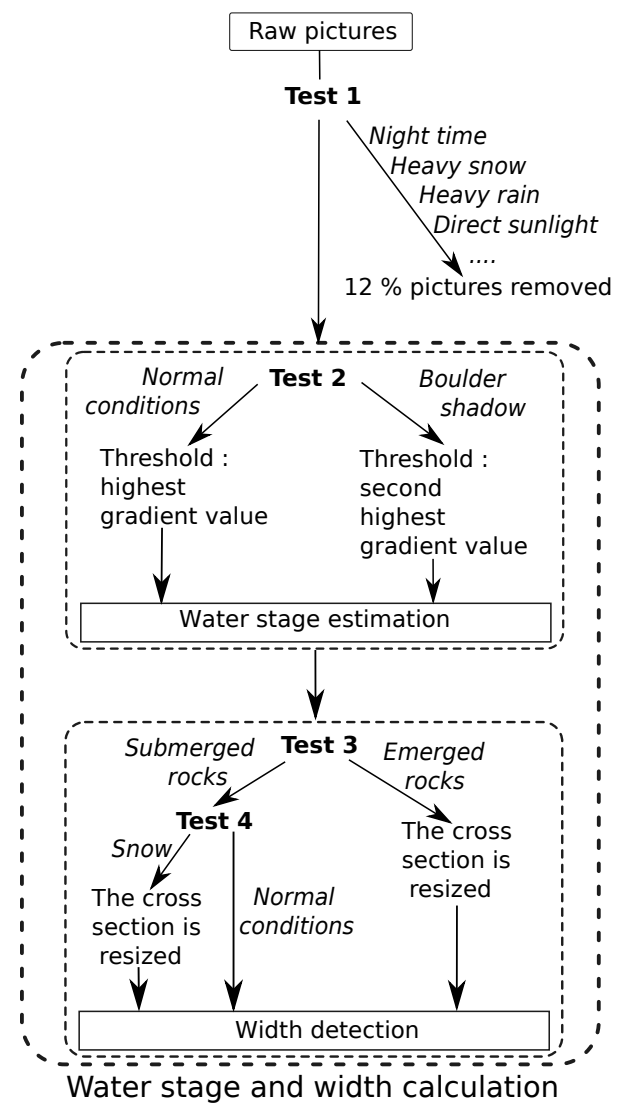

Figure 6. The picture classification process: four different tests are used to remove heavy weather conditions or night pictures from the data set (Test 1), to detect pictures with an important boulder shadow (Test 2), emerged rocks on the main channel at low flow (Test 3 ) or a light snow cover on the edge of the stream (Test 4).

Two main issues interfering with the water edge detection arise: the rocky bottom of the stream (Test 3 ) and snow on the river banks (Test 4). In Fig. 5, target zone 4 is used as a water reference, because this part of the stream always had water even at a very low stage. Target zones 5 and 6 are located where rocks emerge at low flows. The mean value of both target zones is compared to the mean value of the reference zone; the target value less than half the reference zone corresponds to submerged rocks. The threshold based on half the value of the reference zone was set empirically after going through a substantial portion of the data set. As described in Sect. 3.6, the width estimate is based on cross sections and the profile with emerged rocks is resized based on the rock emergence/submergence.

The snow cover on the edge of the stream is detected using Test 4 and target zones 7 and 8 . The test is based on the lighter colour of the snow, mean values on zones 7 and 8 are compared to the mean value of the picture, and snow cover corresponds to brighter values on the target zone. As for the case of emerged rocks, the cross section used for the width detection is resized. 

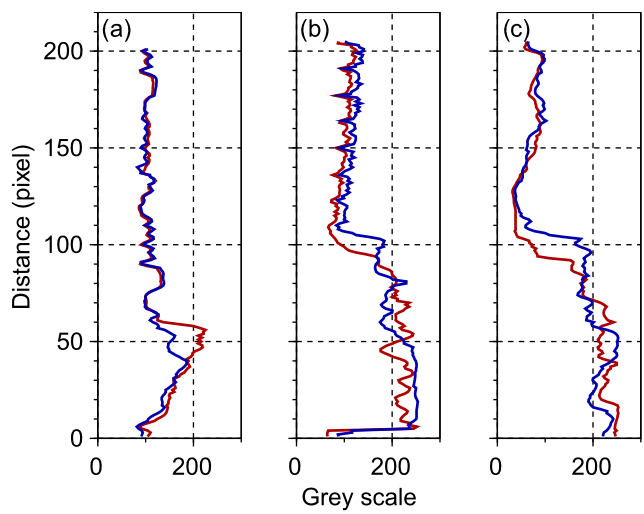

Figure 7. Grey-scale profiles for water surface measurement. (a) The first stage board on the right side of the stream, (b) the second stage board on the left side of the river and (c) on-boulder vertical surface. The red and blue lines show two different water elevations days apart.

The four tests are summarized in Table 1.

\subsection{Water level}

Stage was measured by detecting the water surface line on the images. Instead of a global, manual approach using edge detection (Young et al., 2015), we based the analysis on local site conditions. Black lines in Fig. 3 on both stage boards and the vertical surface of the boulder represent each location where grey-scale profiles from the images were extracted to detect the transition from water to stage board or boulder surface in the image (Fig. 7) and thus locate the water surface in image space.

The water and boulder/stage board transition signal is clear for each water level location. On both stage boards, the image signal is smoother on the water than on the board itself (Fig. 7). However, the transition between rock and water is more obvious on the boulder site (Fig. 7c) than on the left bank stage board (Fig. 7b). On the board located on the right bank of the stream, the transition between the board and the water is not as clear, and the flow stage rise is more difficult to detect. Furthermore, at low stage, the bottom of the scale emerged above the water and the measurement was then impossible. Consequently, this stage board was removed from the analysis. Without the boulder, we would have used the remaining stage board as the water stage estimation but in this particular site the stage board on the far side is used as an independent visual check because the boulder surface gave a clearer signal. We mainly used the boulder station to estimate the flow depth but the boulder is not a requirement for the method and any natural or artificial almost-vertical surface located on the stream could be used.

On the boulder, the water transition corresponds to an obvious inflection point in the image intensity (Fig. 8a) and a local peak in the gradient of the smoothness profile (Fig. 8b).
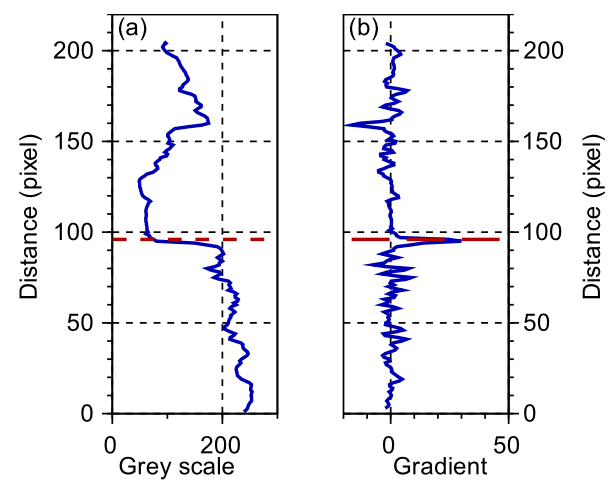

Figure 8. The boulder gauging station profile. The dashed lines represent the water surface. Water is located below those lines. Panel (a) indicates the grey-scale profile and (b) the gradient of the profile; the calculation step is 2 pixels. The gradient plot makes the inflection point and the water level detection easier.

The inflection point is detected using two conditions. The first, on the gradient profile, was used to pick high gradient values. The second condition was based on a grey shade threshold so that only the lowest values in the grey-scale profile are considered because higher values represent the rock becoming darker when it is wet. Using this combined method, the water line position in pixel coordinates can be automatically detected for each picture. In pictures with the boulder shadow issue (see Sect. 3.2), the second highest gradient point is considered instead of the first.

\subsection{Water depth calibration}

Given that the boulder surface is almost vertical, and roughly perpendicular to the axis of the camera lens, we assume a linear relationship between the stage and the water surface position in pixel coordinates: Eq. (1), where $H_{\mathrm{m}}$ is the stage in metres and $d_{\text {pixel }}$ the water surface position on the picture in pixels.

$H_{\mathrm{m}}=a \cdot d_{\text {pixel }}+b$

The slope $a$ of Eq. (1) is given by the millimetres-pixel $\left(\mathrm{mm} \mathrm{px}^{-1}\right)$ relationship extracted from the pictures. The camera is fixed; therefore, the value is consistent through the entire picture set. Using a measuring device (large ruler) on the boulder surface, we get $a=5.5 \times 10^{-3} \mathrm{~m} \mathrm{px}^{-1}$.

To determine the intercept (b) of Eq. (1), which is the ground reference of the flow stage, we used part of the stage logger data set, taking 100 values randomly, to extract the intercept $b=-1.25 \mathrm{~m}$. This gives a local datum for the boulder stage. We also calibrated the stage board located on the side of the boulder on the far side of the picture. This water depth calibration is relative to this gauging station and particular to the site. 
Table 1. The four different picture classification tests. The standard deviation ranges from 0 to 255 . Thresholds are set using both particular and normal condition pictures. The different areas have been chosen to avoid parameter distribution overlap between normal and particular conditions (see the Supplement).

\begin{tabular}{|c|c|c|c|c|}
\hline $\begin{array}{l}\text { Test } \\
\text { number }\end{array}$ & $\begin{array}{l}\text { Target area } \\
\text { (Fig. 4) }\end{array}$ & Picture issue & $\begin{array}{l}\text { Conditions (the test is failed if the con- } \\
\text { dition is fulfilled) }\end{array}$ & Action if test failed \\
\hline 1 & 1 & $\begin{array}{l}\text { Nighttime, heavy } \\
\text { rain, snow... }\end{array}$ & Standard deviation lower than 20 & Removed from the data set \\
\hline 2 & $2-3$ & Boulder shadow & $\begin{array}{l}\text { Area 2: mean value higher than } 235 \\
\text { - indicating almost direct reflection on } \\
\text { the water surface Area } 3: \text { mean value } \\
\text { lower than } 95 \text { - indicating a dark area } \\
\text { on the boulder surface }\end{array}$ & $\begin{array}{l}\text { The water detection is based on the } \\
\text { second highest gradient point in- } \\
\text { stead of the first }\end{array}$ \\
\hline 3 & $4-5-6$ & $\begin{array}{l}\text { Emerged rocks on the } \\
\text { main stream }\end{array}$ & $\begin{array}{l}\text { Area } 4 \text { is the water colour reference } \\
\text { value Areas } 5 \text { and } 6: \text { the mean value is } \\
\text { less than half of the reference value }\end{array}$ & $\begin{array}{l}\text { The width calculation profile is re- } \\
\text { sized }\end{array}$ \\
\hline 4 & $7-8$ & $\begin{array}{l}\text { Light snow cover on the } \\
\text { edge of the stream }\end{array}$ & $\begin{array}{l}\text { Areas } 7 \text { and } 8 \text { : the mean value is higher } \\
\text { than the average of the entire picture } \\
\text { and the standard deviation of both area } \\
\text { is less than } 50 \text { (indicating a smooth } \\
\text { area) }\end{array}$ & $\begin{array}{l}\text { The width calculation profile is re- } \\
\text { sized }\end{array}$ \\
\hline
\end{tabular}

\subsection{Stage validation}

Figure 9a shows the comparison between the transducer data set $\left(H_{\text {transducer }}\right)$ and the camera data set $\left(H_{\text {camera }}\right)$. The stage prediction from picture analysis is a good estimation of the transducer water level $(R=0.91)$. The water measurement using the stage board located on the side of the boulder with a proper calibration has a lower correlation coefficient $(R=0.71)$. The mean value of the difference of the transducer data set and the camera data set is $\mu=0.00 \mathrm{~m}$ and the standard deviation is $\sigma=0.02 \mathrm{~m}$. Considering a normal distribution (Fig. 9b), the $95 \%$ confidence interval on the error estimation is $[-0.04 ; 0.04] \mathrm{m}$ (the error estimation for the stage board measurement is $[-0.06 ; 0.06 \mathrm{~m}])$. Pictures corresponding to the cluster of outliers have been manually checked. Those points correspond to pictures where the water surface is correctly detected but corresponds to waves at the gauging station or at the pressure transducer.

At very low discharge, boulder clusters emerge near the left bank creating pools and small channels. This channel configuration creates a pond at the water level logger at very low discharge and probably disconnects the water stage measured using the image analysis from that of the pressure transducer.

Based on this result, the stage measured from image analysis gives a good estimation of the water stage. The high- and low-frequency variations (i.e. daily or monthly variations) on the transducer signal are well reproduced by the camera data set (Fig. 10). The daily snow/ice melt hydrograph which is characteristic of the site, with consistent times of low and high flow each day in the absence of rainstorms, is also shown in Fig. 10.
While the results show that the image-based time-lapse method works well, there are some errors that could be reduced. The hypothesis for our stage measurement and the water depth calibration equation is the constant $\mathrm{mm} \mathrm{px}^{-1}$ relationship over the boulder surface. The underlying assumptions are that the vertical surface is flat and the camera distortion does not induce a large variation. Realistically, as the boulder is a natural rock, the vertical face is not exactly vertical and we are not able to estimate the distortion variation. The probable inconstant $\mathrm{mm} \mathrm{px}^{-1}$ relationship may induce the tilt on the scatter plot (Fig. 9a and c). The comparison with the transducer data set shows that at high discharges the camera data set underestimates the transducer data set and at low discharges the camera data set overestimates the transducer data set. The $\mathrm{mm} \mathrm{px}^{-1}$ variations could induce the slightly curved shape of the scatter plot (Fig. 9), but only a better camera resolution (or image scale) and a more precise geometry between camera and vertical calibration surface would improve the $\mathrm{mm} \mathrm{px}^{-1}$ relationship.

\subsection{Water width measurement}

Using the time-lapse images we also estimated the water surface width. As we did for the stage, width was measured by detecting the threshold between the river and the rocks on both banks. During the field work, flow width was also calibrated on one cross section. For picture analysis, considering the rocks masking the view of the water surface and standing waves in the flow, the measurement cross section was moved about $2 \mathrm{~m}$ downstream, keeping the same angle across the channel as the calibrated profile (Fig. 11).

On both sides of the stream, some boulders appear at low discharges that are too large to be mobilized by daily high 

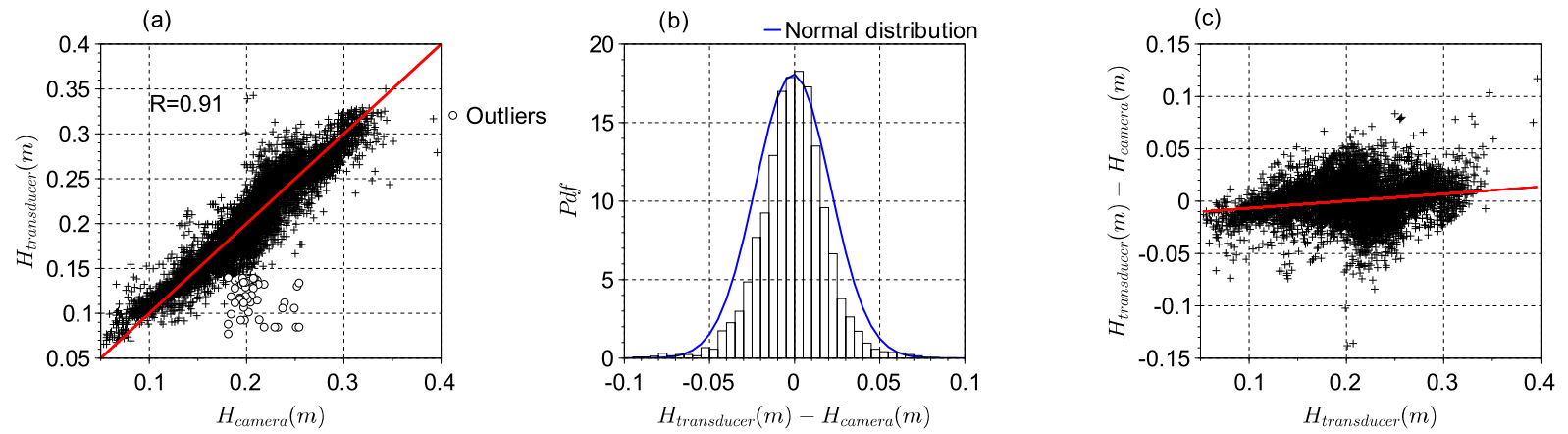

Figure 9. a)Comparison of the transducer data set $\left(H_{\text {transducer }}\right)$ and the camera data set $\left(H_{\text {camera }}\right)$ on the scatter plot; the cluster of outliers point represented with open symbols has been manually checked and corresponds to waves at the pressure transducer. (b) The error distribution; the normal distribution is set to a mean value of $0.00 \mathrm{~m}$ and a standard deviation of $0.02 \mathrm{~m}$. (c) The residual plot of $H_{\text {transducer }}-H_{\text {camera }}$ with regard to $H_{\text {transducer }}$; the red line represents the linear regression, showing a tilt on the water depth estimation. At high discharges, the camera data set underestimates the transducer data set and at low discharges the camera data set overestimates the transducer data set.

(a)

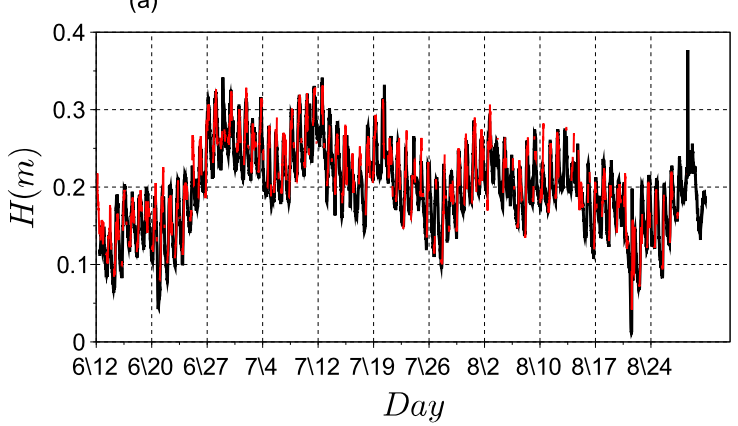

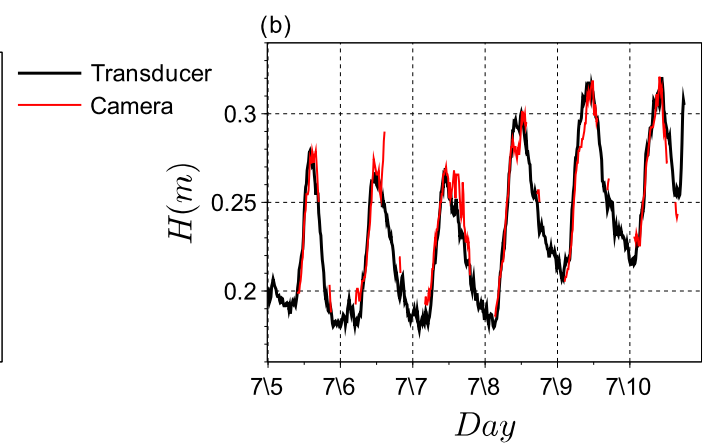

Figure 10. Summer 2015 stage time series. The black line represents the transducer data set $\left(H_{\text {transducer }}\right)$ and the red line is the camera data set $\left(H_{\text {camera }}\right)$. The estimated error on the camera stage relative to pressure transducer is around $3 \mathrm{~cm}$. Panel (a) shows data from mid-June to the end of July 2015. The camera data set fits the transducer data set. The daily trend as well as the general monthly trend are reproduced (b) from 5 to 10 July 2015. At hourly resolution, the trend of the camera stage follows the transducer data closely. However, on the rising stage, the camera data set underestimates the transducer water stage, and on the falling stage, the picture data set slightly overestimates the transducer stage.

flows. On both rocky areas, a test was done to detect if the rocks had emerged (Tests 3 and 4; Fig. 6). If they had, the interrogation area was changed accordingly. On the profile, and as with the water stage, the highest gradient of the greyscale plot profile was used to detect water edges.

\subsection{Water width calibration}

A measuring tape was extended across the entire Dome stream. The distance across the channel was measured in $0.5 \mathrm{~m}$ intervals and the image distance in pixels was converted to metres (Fig. 12).

The conversion from distance in pixels to distance in metres is done using Eq. (2), where $D_{\text {pixel }}$ is the distance in pixels extracted from the picture analysis and $D_{\mathrm{m}}$ the distance in metres. The measuring tape was not perfectly straight due to the inherent limitations of field work such as the flow conditions and channel structure; therefore, the conversion into metres may be slightly inconsistent, which could induce the shift in Fig. 10 around $D_{\text {pixel }}=200$.

$D_{\mathrm{m}}=0.05 \times\left(D_{\text {pixel }}-10\right)^{0.95}+0.45$

The width measurement faces two principal issues: the water edge detection and the calibration. The width measurement is tightly linked to the boulders on the side of the stream. As the stream widens, the boulders at the channel edge are submerged and the grey-scale shift at the edge of the water is less sharp. Inaccurate detection cannot be corrected because of a lack of field validation data for the water width.

The calibration is very sensitive to the camera position. Additional information on camera angle and geometry would increase the calibration accuracy and improve the width measurement. Furthermore, moving the cross section a small distance away from the calibrated cross section induced some 


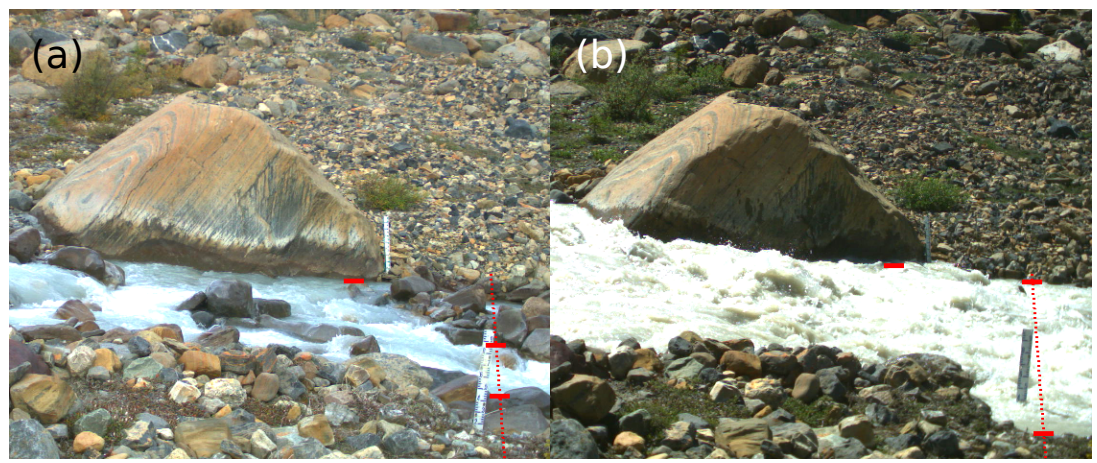

Figure 11. The width measurement at low (a) and high (b) discharges. The left line is the water level at the boulder station. The dashed line is the cross section and the right ticks are the detected flow edges.

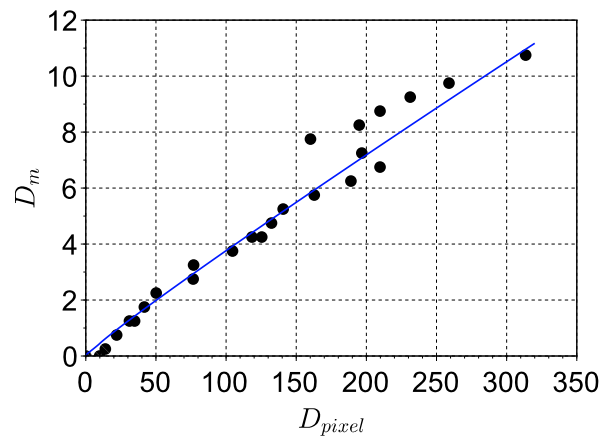

Figure 12. The pixel-metre conversion. $D_{\text {pixel }}$ is the flow width in pixels and $D_{\mathrm{m}}$ is the flow width in metres. The rating curve was established using a measuring tape across the flow width. The data set has been fitted using Eq. (2).

error on the conversion length in metres from length in pixels. Nevertheless, with some refinement, as the distortion of the picture (due to the angle, camera setting which defines the pixel-metre conversion) is a monotone function, there is no major effect on the relative width variations.

\subsection{The width observations}

At very low discharges, the stream bed is covered by large boulders, clearly seen in the pictures, and rocks are fully submerged at high flows, creating large surface waves. The transition between low and high flows creates secondary channels, and we chose to only consider the main channel and not the side channels at low and medium flows. This induces an underestimation of the width at low discharges. The flow widening is also strongly impacted by those boulder clusters. At low discharge, the main channel is contained in the centre of the bed, and water stage has to be quite high to be over both clusters. The transition between wide and narrow channels is fast, and therefore intermediate widths (between 4 and $7 \mathrm{~m}$ wide) are underrepresented in the width data (Fig. 13). The image information reveals these aspects of the

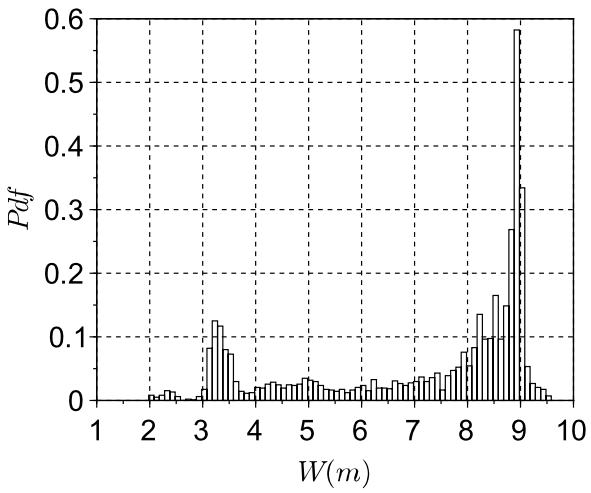

Figure 13. The distribution of measured width. The median class ranging from 4 to $7 \mathrm{~m}$ is underrepresented because boulder clusters on each side of the stream make the transition between narrow flows and wide flows fast and nonlinear.

hydraulics of the channel (and that affect stage changes) that would not be known with stage data alone.

\subsection{The width-stage relationship}

In braided channel studies, the wetted surface measurement has been used as a substitute for stage to estimate the discharge (Smith et al., 1996; Ashmore and Sauks, 2006; Gleason et al., 2015). Previous studies have shown the correlation between the wetted surface and the discharge with an exponent from 0.5 (Smith et al., 1996) to 1 (Ashmore and Sauks, 2006). The width response to discharge change is much higher in these braided channels than in many other streams and this gives the potential for using width in addition to, or instead of, stage changes as the primary variable for estimating discharge. In the Dome stream case, although it is not a braided stream, the relatively shallow cross section also gives significant widening of flow with increasing stage and the positive trend is clear with an exponent close to 0.6 (Fig. 14). However, the trend is not linear and data scatter is quite large because of the irregular geometry of 


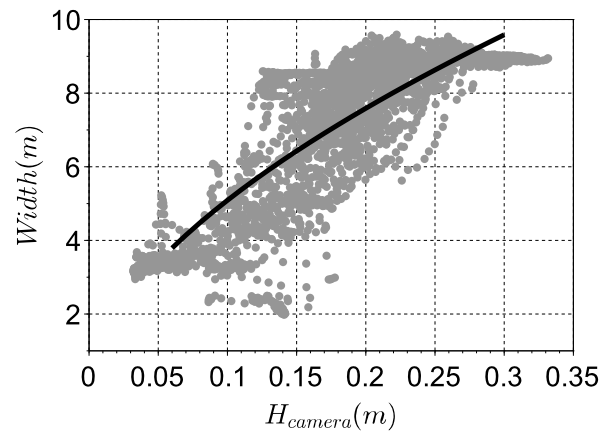

Figure 14. The water surface width as a function of the water height. The stage is taken from the camera data set. The flow width is taken from the width detection and Eq. (2). The trend line equation is $W=19.19 H_{\text {camera }}^{0.58}$

the cross section and the bouldery channel edges (especially at low discharge). Nevertheless, the width estimation could be a reliable approximation to the stage measurement. Even if not used directly as a discharge surrogate, the width data give additional information on the hydraulic geometry of the channel that would be difficult to predict theoretically for this type of channel.

The width data also reveal some interesting hysteresis in the flow hydraulics. For $67 \%$ of the 81 daily flow peaks on the Dome stream for which there are data, the mean value of the stream width over the water stage ranges from strictly higher than one-half $H_{\max }$ and $H_{\max }, H_{\max }$ being the daily maximum water stage, and is higher on the falling limb of the daily hydrograph than on the rising limb. The width increase ranges from 0.5 to $26 \%$, with a mean value of $13.9 \%$ and a median value of $9.1 \%$.

This produces an obvious hysteresis loop in the widthstage plot (Fig. 15), as can often be found in the stagedischarge relationship (Petersen-Øverleir, 2006). The width data derived from image analysis add further information about the channel hydraulics resulting from the complexity of flow associated with the macro-roughness elements in this type of flow.

\subsection{Practical aspects of implementing the method}

The method we are presenting here requires some field work and some post-processing of the pictures.

The field work, including the site choice, the installation of the equipment and the on-site calibration, can be done in a few hours using two people.

Our method is strongly dependent on the picture classification to retain those that are most reliable for water stage and water width detection. The picture classification is based on interest zones linked to environmental and lighting conditions (night, rain/snow, shadows, water reflection and snow cover), and eight different areas were necessary to classify pictures at our site. Each area has to be chosen related to a

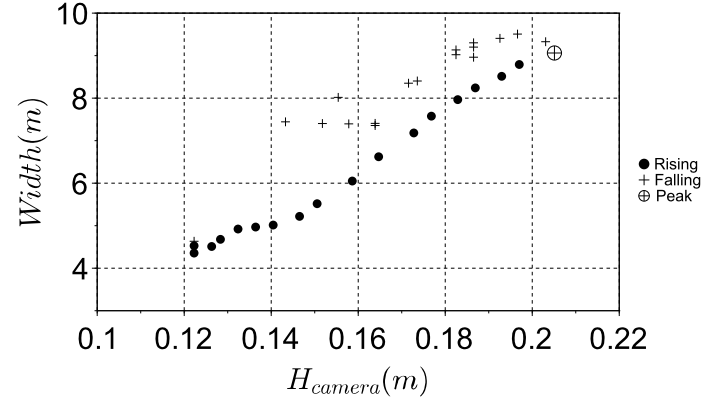

Figure 15. The water surface width as a function of water stage, for falling flows $(+)$, rising flows $(\bullet)$ and the discharge peak $(\oplus)$. The graph shows that for a given water level $\left(H_{\text {camera }}\right)$ the water surface is wider with falling flow than with rising flow conditions. The end of the falling flows usually happens at night; therefore, the data are missing.

particular image issue. For example, to detect nighttime the entire picture can be used, while detection of exposed rocks in the stream channel requires specific small areas of the images. These characteristics are site specific and it takes some trials to identify appropriate criteria and thresholds. However, once established, the actual classification can be done in a few hours and can be used for the same site for extended time periods and repeated installations.

\section{Discussion}

The method described in this paper is similar to two recent studies proposed by Gleason et al. (2015) and Young et al. (2015), but it differs in general approach, field data and image selection, and processing. Young et al. (2015) assumed a $V$ shape of their studied cross section, so that the edge coordinate is linearly related to the water stage. They estimate the water level from the water edge, without on-site validation data, and use a statistical estimation procedure combined with assumed channel geometry to derive water level changes. In the Dome stream case and with width measurement, the water stage and water width are not linearly related, which gives information on the stream cross section despite the lack of topographic survey and shows that assumptions of the type used by Young et al. (2015) would not be reliable in this case. It also points to the difficulty of reliably predicting flows using a standard resistance assumption in this type of channel. In addition, Young et al. (2015) use manual methods to identify water edges on all images. Gleason et al. (2015) focus on water area detection in a large braided channel and not on direct water stage measurements or on small, steep channels.

The environmental conditions (e.g. Sun position, fog, rain) are the main common difficulties that reduce the picture quality and therefore picture filtering as an important step in the process. Gleason et al. (2015) and Young et al. (2015) 
identify similar issues but adopt different approaches. Young et al. (2015) use manual image selection in contrast to our automated selection procedures which make it possible to process a much larger image set and derive much higherfrequency data (15 min vs. $4 \mathrm{~h}$ ). Gleason et al. (2015) adopt semi-automated image procedures which differ in detail from ours but their procedures result in either retention or rejection of images for measurement, whereas we derive alternative detection criteria (cross-section resizing, peak detection, etc.; see Table 1) for a subset of images rather than eliminating them completely from the data set. Consequently, we are able to retain much higher-frequency monitoring relative to Gleason et al. (2015). Field data on the site characteristics avoid having to make assumptions about the site, such as the cross-section shape (Young et al., 2015), or working without any ground data for validation (Gleason et al., 2015).

Improved image acquisition is the key component for improving remote sensing accuracy and time coverage. The use of inexpensive time-lapse cameras introduces some limitations that can be mitigated. A higher image resolution and a better camera position (reducing sunlight effects or improving the position relative to the calibration surface, for example) would improve the measurement accuracy for both the water stage and the channel width. These refinements are easy to implement and test.

Another obvious limitation is the restriction on daytime images. In the Dome case, night and twilight represent roughly one-third of the day in the summer meltwater period for which data are needed. Using a night-vision camera may extend the effective monitoring times, but we have not tested this. The limitation may be less significant if only certain flow information is needed rather than a $24 \mathrm{~h}$ continuous signal. Even without continuous data, useful information on channel hydraulics can also be obtained from this type of monitoring. These procedures and image processing steps may be changed to fit site characteristics or data needs. In this case, the method provided the necessary seasonal stage signal and timing of daily peaks needed for the study objective of comparison between the ungauged tributary and the main channel flow.

\section{Conclusions}

The results demonstrate the effectiveness of a simple measurement apparatus for flow stage and water surface width: a low-cost time-lapse camera and a few simple field measurements. Fully automatic image processing to select images and to detect the water level and edges makes it possible to process a large number of images to produce a long, high-temporal-resolution data set. It shows that reliable water stage and water width measurement can be measured at small (minutes) time steps over 3 months in this case. The estimated hydraulic parameters reliably reproduce the hourly, daily and monthly variations in flow of this pro-glacial river compared to pressure-transducer stage data. The low cost of the camera (approximately USD 600) and the very easy data collection make the image processing a powerful tool for this type of river monitoring especially on small headwater streams. Image analysis produced a larger variety of data and information than a simple water stage transducer alone can yield. Indeed, pictures provide visible data such as weather conditions (snow cover, freezing conditions, rain), water surface conditions (surface waves, eddies, jumps) and details of the flow hydraulics and geometry over the full range of discharge. Image analysis could also be extended to other hydraulic measurements such as the water slope. The method extends the available methods for inexpensive terrestrial remote sensing of river flow at high-frequency and extended time periods applicable especially to small channels with complex flow.

Data availability. The data used in this study are available in the online Supplement.

\section{The Supplement related to this article is available online at https://doi.org/10.5194/hess-22-1-2018-supplement.}

Competing interests. The authors declare that they have no conflict of interest.

Acknowledgements. This research was supported by a Natural Sciences and Engineering Research Council of Canada Discovery Grant to Peter Ashmore. We thank Sarah Peirce, Lara Middleton and Matilde Welber for field work assistance, and Tobi Gardner for help with the water level logger.

Edited by: Christian Stamm

Reviewed by: David Young and two anonymous referees

\section{References}

Ashmore, P. and Sauks, E.: Prediction of discharge from water surface width in a braided river with implications for at-astation hydraulic geometry, Water Resour. Res., 42, W03406, https://doi.org/10.1029/2005WR003993, 2006.

Bertoldi, W., Piégay, H., Buffin-Bélanger, T., Graham, D., and Rice, S.: Applications of Close-Range Imagery in River Research, in: Fluvial Remote Sensing for Science and Management, John Wiley \& Sons, Ltd, 341-366, https://doi.org/10.1002/9781119940791.ch15, 2012.

Creutin, J., Muste, M., Bradley, A., Kim, S., and Kruger, A.: River gauging using PIV techniques: a proof of concept experiment on the Iowa River, J. Hydrol., 277, 182-194, https://doi.org/10.1016/S0022-1694(03)00081-7, 2003. 
Gleason, C. J. and Smith, L. C.: Toward global mapping of river discharge using satellite images and at-many-stations hydraulic geometry, P. Natl. Acad. Sci. USA, 111, 4788-4791, https://doi.org/10.1073/pnas.1317606111, 2014.

Gleason, C. J., Smith, L. C., Finnegan, D. C., LeWinter, A. L., Pitcher, L. H., and Chu, V. W.: Technical Note: Semi-automated effective width extraction from time-lapse RGB imagery of a remote, braided Greenlandic river, Hydrol. Earth Syst. Sci., 19, 2963-2969, https://doi.org/10.5194/hess-19-2963-2015, 2015.

Hauet, A., Kruger, A., Krajewski, W. F., Bradley, A., Muste, M., Creutin, J.-D., and Wilson, M.: Experimental system for realtime discharge estimation using an image-based method, J. Hydrol. Eng., 13, 105-110, 2008.

Javernick, L., Brasington, J., and Caruso, B.: Modeling the topography of shallow braided rivers using Structure-fromMotion photogrammetry, Geomorphology, 213, 166-182, https://doi.org/10.1016/j.geomorph.2014.01.006, 2014.

MacVicar, B. J., Hauet, A., Bergeron, N., Tougne, L., and Ali, I.: River Monitoring with Ground-Based Videography, in: Fluvial Remote Sensing for Science and Management, John Wiley \& Sons, Ltd, 367-383, https://doi.org/10.1002/9781119940791.ch16, 2012.

Petersen-Øverleir, A.: Modelling stage-discharge relationships affected by hysteresis using the Jones formula and nonlinear regression, Hydrolog. Sci. J., 51, 365-388, 2006.

Ran, Q.-H., Li, W., Liao, Q., Tang, H.-L., and Wang, M.-Y.: Application of an automated LSPIV system in a mountainous stream for continuous flood flow measurements, Hydrol. Process., 30, 3014-3029, https://doi.org/10.1002/hyp.10836, 2016.
Smith, L. C., Isacks, B. L., Bloom, A. L., and Murray, A. B.: Estimation of Discharge From Three Braided Rivers Using Synthetic Aperture Radar Satellite Imagery: Potential Application to Ungaged Basins, Water Resour. Res., 32, 2021-2034, https://doi.org/10.1029/96WR00752, 1996.

Stumpf, A., Augereau, E., Delacourt, C., and Bonnier, J.: Photogrammetric discharge monitoring of small tropical mountain rivers: A case study at Rivière des Pluies, Réunion Island, Water Resour. Res., 52, 4550-4570, https://doi.org/10.1002/2015WR018292, 2016.

Tsubaki, R., Fujita, I., and Tsutsumi, S.: Measurement of the flood discharge of a small-sized river using an existing digital video recording system, J. Hydro-Environ. Res., 5, 313-321, https://doi.org/10.1016/j.jher.2010.12.004, 2011.

Williams, R., Brasington, J., Vericat, D., Hicks, M., Labrosse, F., and Neal, M.: Chapter twenty-monitoring braided river change using terrestrial laser scanning and optical bathymetric mapping, Developments in Earth Surface Processes, 15, 507-532, 2011.

Young, D. S., Hart, J. K., and Martinez, K.: Image analysis techniques to estimate river discharge using time-lapse cameras in remote locations, Comput. Geosci., 76, 1-10, https://doi.org/10.1016/j.cageo.2014.11.008, 2015. 